\title{
Migración ambiental: un asunto emergente en América Latina. Caso México
}

Environmental migration: an emerging issue in Latin America. Mexico case

\author{
Dra. María Teresa MONTALVO ROMERO \\ Universidad Veracruzana \\ Xalapa, Veracruz, México. \\ tmontalvo@uv.mx
}

\author{
Ana Paola ROMÁN HERNÁNDEZ \\ Universidad Veracruzana \\ Xalapa, Veracruz, México \\ paolaroman18@gmail.com
}

\begin{abstract}
Resumen: En la actualidad, la comunidad internacional se enfrenta a un escenario rodeado de riesgos globales: cambio climático, delincuencia organizada, trata de personas, migraciones ambientales desencadenadas por el aumento del nivel del mar, desertificación, falta de agua, entre otros. La región latinoamericana ha puesto especial énfasis en las migraciones ambientales, enfocándose en que, los flujos migratorios han ido modificándose a lo largo del siglo XXI, descubriendo que ahora los impactos ambientales establecen un vínculo entre cambio climático y migración. México también tendrá que ir adaptándose a las condiciones presentes, lo que conlleva a plantear una serie de retos importantes para el Estado mexicano.
\end{abstract}

Abstract: At present, the international community faces a scenario surrounded by global risks: climate change, organized crime, human trafficking, environmental migrations triggered by rising sea levels, desertification, lack of water, among others. The Latin American region has placed special emphasis on environmental migrations, focusing on the fact that migratory flows have been changing throughout the 21 st century, discovering that now environmental impacts establish a link between climate change and migration. Mexico will also have to adapt to current conditions, which entails posing a series of important challenges for the Mexican State.

Palabras clave: Migración, América Latina, políticas públicas, gobernanza. 
Keywords: Migration, Latin America, public policies, governance.

Sumario:

I. Introducción.

II. Relación entre cambio climático y migración.

III. Experiencias en Latinoamérica en relación con los migrantes ambientales.

IV. Situación actual en México: Desafíos para la creación de una política pública.

V. Reflexiones finales sobre la generación de política pública en materia de migración climática.

VI. Bibliografía.

Recibido: septiembre 2020.

Aceptado: noviembre 2020. 


\section{INTRODUCCIÓN}

En la sociedad actual el medio ambiente juega un papel protagónico en las agendas de los Estados a nivel internacional, hecho derivado de que el cambio climático ${ }^{1}$ ha intensificado la frecuencia e intensidad de fenómenos meteorológicos extremos.

En ese contexto, la comunidad internacional hace un llamado hacia una nueva gobernanza donde los países se comprometen bajo el Acuerdo de París de 2015 y la Agenda 2030 de Desarrollo Sostenible, a estrechar los lazos de cooperación para lograr el desarrollo sostenible que involucre las esferas económica, social y ambiental para poder hablar de un modelo de desarrollo sostenible.

Una de las consecuencias más visibles del cambio climático es, que ha derivado en desastres naturales recurrentes que perjudican la calidad de vida y el patrimonio e integridad de las personas, obligándolas a tener que migrar de sus lugares de origen por motivos económicos, políticos, culturales y ambientales, lo que ha generado la aparición de migrantes climáticos, es decir, "persona o grupos de personas que, debido a la degradación ambiental relacionada con el cambio climático, de aparición repentina o de desarrollo lento, que afecta negativamente a su vida, se ve ante la necesidad de abandonar su hogar, temporal o permanentemente, de manera individual o colectiva y a nivel interno o internacional " 2 .

La aparición de esta figura abre el debate sobre la actuación de las instituciones gubernamentales en materia de protección a los migrantes climáticos, por lo que el objetivo general de este artículo es evidenciar la necesidad de gestionar la

\footnotetext{
${ }^{1}$ Con base en la Convención Marco de las Naciones Unidas sobre el Cambio Climático se entiende como un cambio de clima atribuido directa o indirectamente a la actividad humana que altera la composición de la atmosfera mundial y que se suma a la variabilidad natural del clima observada durante períodos de tiempo comparables (artículo 1).

${ }^{2}$ Véase Organización Internacional para las Migraciones (OIM). Migration, Enviroment and Climate Change: Assessing the evidence, 2009, p. 19 en: https://publications.iom.int/system/ iles/pdf/migration_and_environment.pdf
} 
creación de políticas públicas en México donde las dimensiones ambientales y climáticas sean relevantes en la política migratoria actual, tomando como base las experiencias latinoamericanas.

En ese sentido, el artículo se estructuró en cuatro apartados, el primero establece la relación existente entre cambio climático y migración, el segundo plantea las experiencias en la región latinoamericana sobre migraciones ambientales y el tercero sostiene cuales son los desafíos a los que se enfrenta México. Por último, las reflexiones van encaminadas a pensar en acciones colectivas que generen la participación de diversos actores que fortalezcan el marco institucional para enfrentar los retos del reconocimiento legítimo de este tipo de migrantes.

\section{RELACIÓN ENTRE CAMBIO CLIMÁTICO Y MIGRACIÓN}

En la primera década del siglo XXI, el fenómeno del cambio climático ha ocasionado una serie de desastres naturales recurrentes que perjudican la calidad de vida y el patrimonio de la población en el mundo, amenazando el desarrollo actual y futuro de las naciones.

Los efectos del cambio climático han sido devastadores en diversas partes del mundo y México no es la excepción, y en ese orden de ideas, los impactos de huracanes, inundaciones, deslizamientos, deslaves y otros procesos donde media la naturaleza como principal recurso se irán incrementando año con año. En las últimas dos décadas el número de desastres naturales registrados se han duplicado, de 200 a más de 400 al año. Nueve de cada diez desastres naturales se relacionan con el clima actual. ${ }^{3}$

La comunidad internacional ha constatado que la migración se ha convertido en una estrategia de adaptación al cambio climático, por lo que, en ese tenor, queda claro que el migrante climático es un tema que debe priorizarse en las agendas de los Estados, ya que las cifras confirman su importancia. Entre 1995 y 2015 se registraron 6,457 desastres relacionados con el clima, que acabaron con cerca de 606, 000 vidas y afectaron a más de 4,000 millones de personas, muchas de las cuales se quedaron sin hogar. ${ }^{4}$

${ }^{3}$ Para más información consulte HOLMES, SIR JOHN Secretario General Adjunto de Asuntos Humanitarios y Coordinador del Socorro de Emergencia, Comentario de apertura en la exposición de ayuda humanitaria internacional y conferencia de desarrollo de Dubái "Conferencia DIHAD 2008", 8 de abril de 2008. Disponible en: http://www.reliefweb.int/ rwarchive/ rwb.nsf/db900sid/YSAR-7DHL88?OpenDocument. 8.

${ }^{4}$ Véase Centre for Research on the Epidemiology of Disasters - The United Nations Office for Disaster Risk Reduction (CRED- UNISDR). The human cost of weather-related disasters 19952015, Louvain 2016, p. 5. 
La aparición del migrante climático hace necesario cuestionarse que estrategias están adoptándose para hacerle frente a esta problemática, ya que con base en datos del Panel Intergubernamental de Expertos sobre Cambio Climático de la ONU (IPCC) el cambio climático ya está generando efectos sobre todo en los países más pobres, aquellos con menor capacidad de adaptación y responsabilidad con respecto al cambio climático. Estos seguirán siendo los más vulnerables ya que su economía sufre de altos niveles de dependencia, la mayor parte del PIB proviene de sectores sensibles al cambio climático como son la agricultura y la pesca, el nivel educativo es bajo y sus capacidades institucionales, económicas, técnicas y financieras son limitadas. ${ }^{5}$

No obstante, nos parece interesante retomar el planteamiento que realiza la Organización para la Cooperación y el Desarrollo Económicos (OCDE), CEPAL (Comisión Económica para América Latina y el Caribe) y el Banco de Desarrollo de América Latina (CAF), en el Informe Perspectivas económicas de América Latina (LEO) en el sentido de que es necesario reconectar a las instituciones con los ciudadanos, respondiendo de mejor manera a sus demandas y aspiraciones, para fortalecer un modelo de crecimiento inclusivo y sostenible en América Latina y el Caribe (ALC). La región debe avanzar hacia instituciones más confiables, más capaces, más abiertas y más innovadoras para continuar con una senda de mayor desarrollo inclusivo ${ }^{6}$.

\section{EXPERIENCIAS EN LATINOAMÉRICA EN RELACIÓN CON LOS MIGRANTES AMBIENTALES}

En Sudamérica se ha demostrado que la migración ambiental es una realidad, así lo podemos observar por la gran diversidad de fenómenos que se han suscitado en Perú, Argentina y Bolivia que han derivado en la adopción de medidas para mitigar la problemática ${ }^{7}$.

De este modo, se hace visible la necesidad que han tenido que enfrentar los países latinoamericanos ante las emergencias climáticas, por lo que fue necesario la creación de normas nacionales y la inclusión de desplazamiento ambiental en sus leyes migratorias y el establecimiento de políticas públicas

\footnotetext{
${ }^{5}$ Véase Panel Intergubernamental de expertos sobre Cambio Climático de la ONU (IPCC), Climate Change 2014. Impacts, Adaptation, and Vulnerability. Summary for Policymakers, p. 5, en: https://www.ipcc.ch/site/assets/uploads/2018/02/ar5_wgII_spm_en.pdf.

${ }^{6}$ VARIOS, Perspectivas económicas de América Latina 2018: Repensando las instituciones para el desarrollo. Editions OCDE, París. Disponible en: http://dx.doi.org/10.1787/leo-2018-es

${ }^{7}$ Véase YAMAMOTO, L., "La migración ambiental en la Agenda 2030 en los planes de Sudamérica: Argentina Bolivia y Perú", en VARIOS, Migraciones en las Américas. Colegio de México, 2019, pp. 415, 416.
} 
para garantizar los derechos de los migrantes ambientales. Tal como se muestra en la siguiente tabla:

Tabla 1. Políticas de los países latinoamericanos relativas a la migración ambiental

\begin{tabular}{|c|c|c|c|}
\hline País & Ley & Artículo & Definición aceptada \\
\hline Bolivia & $\begin{array}{l}\text { Ley de Migración } \\
\text { N}^{\circ} 370,2013 .\end{array}$ & $\begin{array}{l}\text { Art. 65. El Consejo } \\
\text { Nacional de Migración } \\
\text { promoverá la suscripción } \\
\text { de convenios y acuerdos } \\
\text { internacionales en temas } \\
\text { de cambio climático y } \\
\text { medioambiental con los } \\
\text { diferentes Estados, para } \\
\text { la protección de } \\
\text { bolivianos y bolivianas } \\
\text { afectados; asimismo, } \\
\text { coordinará las políticas } \\
\text { públicas que viabilicen, } \\
\text { de ser necesario, la } \\
\text { admisión de migrantes } \\
\text { climáticos. }\end{array}$ & $\begin{array}{l}\text { Migrante climático: } \\
\text { Grupos de personas } \\
\text { que se ven } \\
\text { obligados a } \\
\text { desplazarse de un } \\
\text { Estado a otro por } \\
\text { efectos climáticos, } \\
\text { cuando existe riesgo } \\
\text { o amenaza a su } \\
\text { vida, sea por causas } \\
\text { naturales, desastres } \\
\text { medioambientales, } \\
\text { nucleares, químicos } \\
\text { o hambruna }\end{array}$ \\
\hline Argentina & $\begin{array}{l}\text { Reglamentación } \\
\text { de la Ley de } \\
\text { Migraciones } \mathrm{N}^{\circ} \\
25.871 \text { y sus } \\
\text { modificatorias } \\
\text { (2010) } \\
\text { Decreto 616/2010 } \\
\text { Art. 24, inciso (h) }\end{array}$ & $\begin{array}{l}\text { Art. 24.- Los extranjeros } \\
\text { que ingresen al país } \\
\text { como "residentes } \\
\text { transitorios “podrán ser } \\
\text { admitidos en las } \\
\text { subcategorías } \\
\text { establecidas por el } \\
\text { artículo } 24 \text { de la Ley No } \\
25.871 \text {, con los } \\
\text { siguientes alcances: (...) } \\
\text { h) Especiales: para los } \\
\text { casos en que se justifique } \\
\text { un tratamiento especial, } \\
\text { la Dirección Nacional de } \\
\text { Migraciones podrá dictar } \\
\text { disposiciones de carácter } \\
\text { general que prevean los } \\
\text { recaudos a cumplimentar } \\
\text { para ser admitidos como } \\
\text { residentes transitorios } \\
\text { especiales. } \\
\text { Asimismo, se tendrá en } \\
\text { cuenta la situación de }\end{array}$ & \\
\hline
\end{tabular}




\begin{tabular}{|c|c|c|}
\hline & & $\begin{array}{l}\text { aquellas personas que, a } \\
\text { pesar de no requerir } \\
\text { protección internacional, } \\
\text { transitoriamente no } \\
\text { pueden retornar a sus } \\
\text { países de origen en razón } \\
\text { de las condiciones } \\
\text { humanitarias } \\
\text { prevalecientes o debido a } \\
\text { las consecuencias } \\
\text { generadas por desastres } \\
\text { naturales o ambientales } \\
\text { ocasionados por el } \\
\text { hombre. A este fin } \\
\text { podrán tomarse en cuenta } \\
\text { las recomendaciones de } \\
\text { no retorno que formulare } \\
\text { el ACNUR. }\end{array}$ \\
\hline Perú & $\begin{array}{l}\text { Decreto } \\
\text { Legislativo de } \\
\text { Migraciones } \\
\text { (2017) }\end{array}$ & $\begin{array}{l}\text { Artículo 29. Tipos de } \\
\text { Calidades Migratoria. } \\
\text { (...) 29.2. Residencia: } \\
\text { Autoriza el ingreso y/o } \\
\text { residencia en el territorio } \\
\text { de la República. Estas } \\
\text { Calidades Migratorias } \\
\text { son prorrogables y } \\
\text { permiten múltiples } \\
\text { entradas. Las Calidades } \\
\text { Migratorias de } \\
\text { Residencia son las } \\
\text { siguientes: (...) k. } \\
\text { Humanitaria Para el } \\
\text { extranjero que } \\
\text { encontrándose en } \\
\text { territorio nacional y sin } \\
\text { reunir los requisitos para } \\
\text { acceder a la condición de } \\
\text { asilado o refugiado, se } \\
\text { encuentre en situación de } \\
\text { gran vulnerabilidad o } \\
\text { peligro de vida en caso } \\
\text { de abandono del } \\
\text { territorio peruano o para } \\
\text { quien requiere protección } \\
\text { en atención a una grave } \\
\text { amenaza o acto de }\end{array}$ \\
\hline
\end{tabular}




\begin{tabular}{|c|c|c|}
\hline & & $\begin{array}{l}\text { violación o afectación de } \\
\text { sus derechos } \\
\text { fundamentales. Del } \\
\text { mismo modo, será } \\
\text { aplicable para los } \\
\text { solicitantes de refugio y } \\
\text { asilo o para quienes } \\
\text { hayan migrado por } \\
\text { motivos de desastres } \\
\text { naturales y } \\
\text { medioambientales; o para } \\
\text { quienes han sido víctima } \\
\text { de trata o tráfico de } \\
\text { personas; o para las } \\
\text { niñas, niños y } \\
\text { adolescentes no } \\
\text { acompañados; o para } \\
\text { apátridas. }\end{array}$ \\
\hline Brasil & & $\begin{array}{l}\text { No hay normativa, pero } \\
\text { el Comité Nacional de } \\
\text { Migración puede } \\
\text { conceder una visa por } \\
\text { razones humanitarias. } \\
\text { Por ejemplo, a los } \\
\text { haitianos víctimas del } \\
\text { terremoto de 2010. } \\
\text { El Consejo Nacional de } \\
\text { Inmigración de Brasil } \\
\text { (CNIg) aprobó visas de } \\
\text { residencia permanente a } \\
\text { los ciudadanos haitianos } \\
\text { que llegaron a Brasil tras } \\
\text { el terremoto de enero de } \\
\text { 2010. }\end{array}$ \\
\hline Cuba & $\begin{array}{l}\text { Art. 80, D-5 (b) } \\
\text { del Reglamento } \\
\text { de la Ley de } \\
\text { Migración, de } \\
1978\end{array}$ & $\begin{array}{l}\text { Define como parte de la } \\
\text { clasificación migratoria } \\
\text { "residente temporal “, la } \\
\text { subclasificación } \\
\text { "refugiado", prevista } \\
\text { para las personas que } \\
\text { tienen que abandonar su } \\
\text { país debido a calamidad } \\
\text { social, bélica, } \\
\text { cataclismos u otros } \\
\text { fenómenos de la } \\
\text { naturaleza, y necesitan }\end{array}$ \\
\hline
\end{tabular}




\begin{tabular}{|c|c|c|c|}
\hline & & $\begin{array}{l}\text { "la hospitalidad y } \\
\text { albergue " de la } \\
\text { República de Cuba hasta } \\
\text { tanto desaparezcan las } \\
\text { causas que motivaron la } \\
\text { salida de su país, o sea, } \\
\text { establece explícitamente } \\
\text { una suerte de } \\
\text { condicionamiento } \\
\text { temporal. Esta sub- } \\
\text { clasificación migratoria } \\
\text { fue asignada a los } \\
\text { refugiados haitianos que } \\
\text { solicitaron asilo en Cuba } \\
\text { entre } 1991 \text { y } 1994 \text {, los } \\
\text { cuales fueron asistidos } \\
\text { por el ACNUR en un } \\
\text { proyecto de integración } \\
\text { local. }\end{array}$ & \\
\hline Ecuador & $\begin{array}{l}\text { Ley Orgánica de } \\
\text { Movilidad } \\
\text { Humana (2017) }\end{array}$ & $\begin{array}{l}\text { Artículo 58.- Personas en } \\
\text { protección por razones } \\
\text { humanitarias. Es la } \\
\text { persona extranjera que, } \\
\text { sin cumplir los requisitos } \\
\text { establecidos en la } \\
\text { presente Ley para } \\
\text { acceder a una condición } \\
\text { migratoria, demuestra la } \\
\text { existencia de razones } \\
\text { excepcionales de índole } \\
\text { humanitaria por ser } \\
\text { víctima de desastres } \\
\text { naturales o ambientales. } \\
\text { La persona podrá acceder } \\
\text { a una visa humanitaria } \\
\text { por un lapso de hasta dos } \\
\text { años de conformidad con } \\
\text { el reglamento de esta } \\
\text { Ley, siempre y cuando } \\
\text { no sean considerados una } \\
\text { amenaza o riesgo para la } \\
\text { seguridad interna según } \\
\text { la información que } \\
\text { dispone el Estado } \\
\text { ecuatoriano. } \\
\text { Transcurrido este tiempo, }\end{array}$ & \\
\hline
\end{tabular}




\begin{tabular}{|c|c|c|}
\hline & & $\begin{array}{l}\text { de persistir las razones } \\
\text { por las cuales solicitó la } \\
\text { visa humanitaria, esta se } \\
\text { podrá prorrogar hasta } \\
\text { que cesen los motivos } \\
\text { que dieron origen a la } \\
\text { concesión de la visa, sin } \\
\text { perjuicio de que en } \\
\text { cualquier momento y } \\
\text { previo al cumplimiento } \\
\text { de los requisitos } \\
\text { previstos en esta Ley } \\
\text { pueda acceder a otra } \\
\text { condición migratoria. } \\
\text { (Énfasis agregado }\end{array}$ \\
\hline Guatemala & $\begin{array}{l}\text { Decreto } \\
\text { Código } \\
\text { Migración }\end{array}$ & $\begin{array}{l}\text { Artículo 68. Ingreso de } \\
\text { personas por razones } \\
\text { humanitarias. } \\
\text { a) Por catástrofe natural } \\
\text { en los países vecinos, } \\
\text { que obliga a las personas } \\
\text { o grupo de personas a } \\
\text { salvar sus vidas } \\
\text { b) Por emergencias } \\
\text { médicas (...) } \\
\text { c) Por razones de } \\
\text { conflictos armados, de } \\
\text { acuerdo al derecho } \\
\text { internacional. }\end{array}$ \\
\hline Panamá & $\begin{array}{l}\text { Decreto } \\
\text { Ejecutivo } 34 \\
(1999)\end{array}$ & $\begin{array}{l}\text { Protege a ciudadanos } \\
\text { nicaragüenses que, a raíz } \\
\text { del Huracán Mitch que } \\
\text { azotó Nicaragua, se } \\
\text { encontraban en Panamá } \\
\text { irregularmente. }\end{array}$ \\
\hline Venezuela & & $\begin{array}{l}\text { Para el caso de } \\
\text { ciudadanos haitianos } \\
\text { existen visas } \\
\text { humanitarias desde el } \\
\text { terremoto de enero del } \\
2010 .\end{array}$ \\
\hline
\end{tabular}

Fuente: Elaboración propia con datos del Alto Comisionado de la ONU para los Refugiados. Buenas prácticas: Opciones migratorias para víctimas de desastres naturales, disponible en: https://www.acnur.org/buenas-practicas.html 
Como podemos observar, en la tabla anterior si bien los países latinoamericanos han reconocido la relación existente entre migración, cambio climático y desastres naturales, sólo Bolivia ha incluido en su marco normativo la figura de migrante climático. No obstante, es de reconocer que al menos el tópico ya este inmerso en la agenda pública, lo cual representa un gran avance para estar preparados debido a un desastre natural repentino.

Ahora bien, otra cuestión a resaltar del marco normativo en la región latinoamericana es el gran reto que han asumido por establecer un marco de cooperación entre la región, sin embargo, no hay que obviar que aún existe un mapa incompleto de cooperación en el sistema internacional, puesto que todavía hay brechas significativas que acotar en relación con la participación de naciones desarrolladas por reconocer el fenómeno de la migración ambiental.

Por otro lado, uno de los grandes logros de América Latina que hay que destacar es que cuentan con una plataforma de la sociedad civil, llamada Red Sudamericana para las Migraciones ambientales (Resama) ${ }^{8}$, desde donde se promueve el reconocimiento y la protección de los migrantes ambientales, lo que ya es significativo en la región porque han podido trascender hacia un modelo de organización de la sociedad civil que se hace presente en los diversos foros en materia de migración ambiental.

\section{SITUACIÓN ACTUAL EN MÉXICO: DESAFÍOS PARA LA CREACIÓN DE UNA POLÍTICA PÚBLICA}

Es un hecho que la política ambiental de los países ha estado permeada de cambios, puesto que, hasta hace unas décadas, los problemas ambientales (contaminación, pérdida de especies, deforestación) eran mayormente locales, sin embargo, actualmente nos enfrentamos a problemas ambientales globales, tales como: el cambio climático, la destrucción de la capa de ozono y la contaminación atmosférica por compuestos tóxicos persistentes, y actualmente migrantes ambientales.

En ese contexto, al considerar que el cambio climático es uno de los factores que generan el desplazamiento de las personas que solicitan refugio en otros

\footnotetext{
8 Único miembro del comité consultivo de la Plataforma sobre Desplazamiento por Desastres, que es un seguimiento para la Agenda Nansen. En el ámbito global participa en la construcción de estrategias, políticas y normas para la protección de los migrantes ambientales. Para más información, Véase https://resama.net/.
} 
países, se identifican una serie de actores: En primer lugar, ubicamos al Estado como el principal responsable que debe proveer las condiciones óptimas de disfrute de los derechos y garantizar la promoción, respeto y protección de los Derechos Humanos para contribuir al desarrollo integral de la persona.

Bajo esta lógica, también encontramos inmersos en esta relación a los Organismos Internacionales como la Organización Internacional para las Migraciones (OIM) estableciendo que es posible que el cambio climático exacerbe los desastres repentinos y latentes, así como la degradación ambiental paulatina, motivo por el cual se hace evidente que el Estado asume el papel de gestionar de manera preventiva respuestas que ayuden a resolver la problemática.

Asimismo, también las Organizaciones de la Sociedad Civil juegan un papel fundamental para promover el desarrollo de una agenda pública en materia de migración ambiental, toda vez que, es más común escuchar las voces de la sociedad civil en foros de migración, ante los retos que la misma plantea.

En México, la Constitución Política de los Estados Unidos Mexicanos es la ley suprema y base fundamental del ordenamiento jurídico. Dicha ley, establece los derechos y obligaciones de las y los gobernados, así como la forma de gobierno, la división de poderes y las atribuciones de cada uno de estos.

Bajo ese argumento, la Constitución Política de los Estados Unidos Mexicanos reconoce en su artículo 4o., párrafo quinto, el derecho humano al medio ambiente sano para el desarrollo y bienestar ${ }^{9}$, disposición jurídica que a la letra señala lo siguiente:

"Toda persona tiene derecho a un medio ambiente sano para su desarrollo y bienestar. El Estado garantizará el respeto a este derecho. El daño y deterioro ambiental generará responsabilidad para quien lo provoque en términos de lo dispuesto por la ley “.

Es por ello por lo que, la protección y el cuidado del ambiente se encuentran situadas como prioridades en México, lo cual se ha evidenciado en los Planes Nacionales de Desarrollo (a partir de 1983 a la fecha) y en los diversos tratados internacionales que tiene suscrito en materia de protección al ambiente. Destacando que México fue el primer país en Latinoamérica en

\footnotetext{
${ }^{9}$ Constitución Politica de los Estados Unidos Mexicanos, disponible en:

http://www.diputados.gob.mx/LeyesBiblio/pdf/1_080520.pdf.
} 
crear una Ley General de Cambio Climático $^{10}$, publicada en el Diario Oficial de la Federación el seis de junio de 2012, y que dentro de sus objetivos establece: a) garantizar el derecho a un medio ambiente sano, b) transitar hacia una economía competitiva, sustentable y de bajas emisiones de carbono, c) reducir la vulnerabilidad de la población y los ecosistemas frente a los efectos adversos del cambio climático y d) garantizar la coordinación y transversalidad entre órdenes de gobierno y dependencias de la Administración Pública Federal, con transparencia y participación corresponsable de la sociedad.

Además, nuestro país ha enfatizado la importancia de alinear sus planes y programas a la Agenda 2030: Objetivos de Desarrollo Sostenible (ODS) ${ }^{11}$, mismos que establecen metas y recomendaciones en materia de reducción de riesgo de desastres, cambio climático y migraciones y donde se ha evidenciado que la Agenda solicita a los Estados que refuercen la cooperación internacional para garantizar una migración segura, ordenada y regular con respecto a los derechos humanos de los migrantes, destacando la vulnerabilidad de los migrantes, refugiados y desplazados internos.

Si bien la Agenda 2030 no hace mención explícita a la movilidad humana en el contexto del cambio climático y los desastres, la temática puede encajar bien en los ODS 1.5,10.7, 11 y 13. Como se analiza en la siguiente tabla:

Tabla 2. Relación de los ODS con la migración ambiental

\begin{tabular}{|l|l|}
\hline $\begin{array}{c}\text { OBJETIVO DE } \\
\text { DESARROLLO } \\
\text { SOSTENIBLE }\end{array}$ & \multicolumn{1}{c|}{ CONTENIDO } \\
\hline Objetivo 1.5. & $\begin{array}{l}\text { Establece el fomento de la resiliencia y la reducción de la } \\
\text { exposición al riesgo de las personas y comunidades vulnerables. } \\
\text { Ello implica el desarrollo y mejora de mecanismos de prevención } \\
\text { de desastres y de adaptación a los efectos del cambio climático } \\
\text { que, a su vez, eviten la afectación a los patrones de movilidad } \\
\text { de estos grupos. }\end{array}$ \\
\hline Objetivo 10.7. & $\begin{array}{l}\text { Señala la búsqueda de una migración ordenada, segura, regular y } \\
\text { responsable de las personas. Esto supone enfrentar las causas } \\
\text { que obligan a emprender estos procesos de manera forzada. } \\
\text { En especial si de alguna manera están vinculados a procesos } \\
\text { de desarrollo; como suelen estarlo los desastres ambientales. }\end{array}$ \\
\hline
\end{tabular}

\footnotetext{
${ }^{10}$ Véase Ley General de Cambio Climático, en:

http://www.diputados.gob.mx/LeyesBiblio/pdf/LGCC_130718.pdf

${ }^{11}$ Véase Organización de las Naciones Unidas. Objetivos para el Desarrollo Sostenible, 2015. Disponible en: https://www.un.org/sustainabledevelopment/es/development-agenda/
} 


\begin{tabular}{|l|l|}
\hline $\begin{array}{l}\text { Objetivo 11. } \\
\text { ciudades y } \\
\text { comunidades } \\
\text { sostenibles: }\end{array}$ & $\begin{array}{l}\text { a) Para 2030, reducir el número de muertes y de personas } \\
\text { afectadas por los desastres y reducir las pérdidas económicas } \\
\text { causadas por los desastres, haciendo especial hincapié en la } \\
\text { protección de los pobres y personas vulnerables; b) Para 2020, } \\
\text { aumentar el número de ciudades y asentamientos humanos que } \\
\text { adoptan políticas y planes integrados de mitigación y adaptación } \\
\text { al cambio climático y resiliencia ante desastres, desarrollar y } \\
\text { poner en práctica, en consonancia con el Marco de Sendai la } \\
\text { gestión integral de los riesgos de desastre. }\end{array}$ \\
\hline $\begin{array}{l}\text { Objetivo 13. } \\
\text { Acción por el } \\
\text { clima }\end{array}$ & $\begin{array}{l}\text { a)Fortalecer la resiliencia y la capacidad de adaptación a los } \\
\text { riesgos relacionados con el clima y los desastres naturales; b) } \\
\text { Incorporar medidas relativas al cambio climático en políticas, } \\
\text { estrategias y planes nacionales; c) Mejorar la educación, la } \\
\text { sensibilización y la capacidad humana e institucional en relación } \\
\text { con la mitigación y adaptación del cambio climático, la reducción de } \\
\text { sus efectos y la alerta temprana; d) Aumentar la capacidad de } \\
\text { planificación y gestión en relación con el cambio climático en } \\
\text { los países menos adelantados y pequeños Estados insulares en } \\
\text { desarrollo, centrándose en las mujeres, jóvenes, comunidades } \\
\text { locales y marginadas }\end{array}$ \\
\hline
\end{tabular}

Fuente: Elaboración propia con datos de la Agenda 2030. Disponible en: https://www.un.org/sustainabledevelopment/es/development-agenda/.

En general, podemos deducir que los Objetivos de Desarrollo Sostenible a pesar de no estar relacionados directamente con la migración, si logran establecer la importancia de cumplir cada uno de ellos para una migración segura, ordenada y regular, además de legitimar el fenómeno de cambio climático, como una problemática real.

Finalmente, es importante señalar que en lo que respecta a la normatividad migratoria, las principales instituciones mexicanas encargadas de su gestión son el Instituto Nacional de Migración (INM) y la Comisión Mexicana de Ayuda para los Refugiados (COMAR), sin embargo, hasta el día de hoy ninguna de las dos contempla la figura de migrante ambiental en sus leyes y reglamentos, lo cual evidencia que aún no está visibilizada la problemática en la agenda pública del Estado mexicano.

Lo anterior, nos lleva a cuestionarnos, ¿Por qué si estamos alineados a la Agenda internacional de los ODS, la Plataforma Nansen y otros instrumentos que contemplan la existencia de los migrantes ambientales y la importancia de contar con mecanismos para su protección, ¿aún no contamos con el reconocimiento de esta figura?, ¿ Se pueden generan políticas públicas preventivas para el refugio de estas personas? 
Por otro lado, al considerar que el cambio climático es uno de los principales factores que generan el desplazamiento de las personas que solicitan refugio en otros países, dentro del desarrollo de la investigación, se identifican una serie de actores que participan en la gestión del refugio en México.

Para el caso, de la figura del refugio, México, ha suscrito diversos instrumentos jurídicos internacionales en la materia. El estatuto jurídico internacional de los refugiados se regula en la llamada "Carta Magna del Refugiado ", es decir, la Convención de Ginebra sobre el Estatuto de los Refugiados de 28 de julio de 1951, con su Protocolo de Nueva York, de 31 de enero de 1967, cuyo artículo 1.a).2, define al refugiado de la siguiente manera;

"aquella persona que, debido a fundados temores de ser perseguida por motivos de raza, religión, nacionalidad, pertenencia a un determinado grupo social u opiniones políticas, se encuentre fuera del país de su nacionalidad y hallándose, a consecuencia de tales acontecimientos, fuera del país donde antes tuviera su residencia habitual, no pueda o, a causa de dichos temores, no quiera regresar a él ".

Bajo ese esquema, podemos determinar que este instrumento no va acorde con la realidad actual, puesto que las características y la procedencia de los refugiados han cambiado considerablemente, y todavía no se ha logrado incluir los factores climáticos y ambientales.

A nivel nacional, México cuenta con una serie de instrumentos jurídicos que regulan la actuación de la Comisión Mexicana de Ayuda para los Refugiados (COMAR), que es la institución encargada de proporcionarles asistencia institucional a los refugiados, la cual fue creada en 1984, por decreto presidencial, por la necesidad imperante de proteger a guatemaltecos que llegaron a México en grandes números, a solicitar asilo.

El marco legal que regula la está constituido entre otros por los siguientes: Constitución Política Mexicana de los Estados Unidos Mexicanos, Convención sobre el Estatuto de los Refugiados, Convención Americana sobre Derechos Humanos, Protocolo sobre el Estatuto de los Refugiados, Pacto Internacional de Derechos Económicos, Sociales y Culturales, Pacto Internacional de Derechos Civiles y Políticos, Ley sobre refugiados, protección complementaria y asilo político y la Ley de Migración.

La Ley sobre refugiados, protección complementaria y asilo político ${ }^{12}$ publicada el 27 de enero de 2011, en el Diario Oficial de la Federación establece en su artículo 13, quienes son considerados refugiados:

\footnotetext{
${ }^{12}$ Véase Ley sobre Refugiados, Protección complementaria y Asilo Político, en:
} 
La condición de refugiado se reconocerá a todo extranjero que se encuentre en territorio nacional, bajo alguno de los siguientes supuestos:

I. Que debido a fundados temores de ser perseguido por motivos de raza, religión, nacionalidad, género, pertenencia a determinado grupo social u opiniones políticas, se encuentre fuera del país de su nacionalidad y no pueda o, a causa de dichos temores, no quiera acogerse a la protección de tal país; o que, careciendo de nacionalidad y hallándose, a consecuencia de tales acontecimientos, fuera del país donde antes tuviera residencia habitual, no pueda o, a causa de dichos temores, no quiera regresar a él;

II. Que ha huido de su país de origen, porque su vida, seguridad o libertad han sido amenazadas por violencia generalizada, agresión extranjera, conflictos internos, violación masiva de los derechos humanos u otras circunstancias que hayan perturbado gravemente el orden público, y

III. Que debido a circunstancias que hayan surgido en su país de origen o como resultado de actividades realizadas, durante su estancia en territorio nacional, tenga fundados temores de ser perseguido por motivos de raza, religión, nacionalidad, género, pertenencia a determinado grupo social u opiniones políticas, o su vida, seguridad o libertad pudieran ser amenazadas por violencia generalizada, agresión extranjera, conflictos internos, violación masiva de los derechos humanos u otras circunstancias que hayan perturbado gravemente el orden público.

En concordancia con esta ley, la Ley de migración ${ }^{13}$ reconoce en su artículo 3 fracción XXII, como Refugiado: "a todo extranjero que se encuentre en territorio nacional y que sea reconocido como refugiado por parte de las autoridades competentes, conforme a los tratados y convenios internacionales de que es parte el Estado Mexicano y a la legislación vigente “.

Asimismo, el Reglamento de la ley sobre refugiados y protección complementaria publicado en el Diario Oficial de la Federación el 21 de febrero de 2012, establece en sus artículos 4, 5 y 6 que se debe entender por temores fundados en cada uno de los supuestos citados anteriormente.

Tomando en consideración esta definición, se puede observar que no se contempla en la legislación nacional el concepto de refugiado ambiental ni en la Ley de migración, ni en la Ley sobre refugiados, protección complementaria y asilo político, lo que nos permite visualizar que el Estado mexicano no contempla

\footnotetext{
http://www.diputados.gob.mx/LeyesBiblio/pdf/LRPCAP_301014.pdf.

${ }^{13}$ Véase Ley de Migración, en:

http://www.diputados.gob.mx/LeyesBiblio/pdf/LMigra_130420.pdf.
} 
la migración ambiental como un problema emergente y por lo tanto se limita a sí mismo para hacer frente a esta situación cada vez más recurrente.

\section{REFLEXIONES FINALES SOBRE LA GENERACIÓN DE POLÍTICA PÚBLICA EN MATERIA DE MIGRACIÓN CLIMÁTICA}

Con base en la investigación documental se identifica que ante una realidad cambiante a nivel mundial como a la que hoy día se enfrenta la sociedad es necesario desarrollar una capacidad de respuesta acorde a los nuevos riesgos globales.

Ello implica asumir un grado de certidumbre y la transformación de los modelos de gestión para conseguir adaptar las relaciones entre la sociedad y el entorno a los nuevos escenarios ambientales. En ese contexto, las conclusiones a las que se llegan al término del documento son las siguientes:

La primera derivada de la agenda ambiental en México, la cual se encuentra alineada a la Agenda 2030: Objetivos para el Desarrollo Sostenible sobre todo en el objetivo 13. Acción por el clima. A partir de ahí, se destaca que México necesita adoptar un concepto de migrante ambiental que permita gestionar de manera efectiva, bajo un marco de gobernanza ambiental, la actuación del Estado mexicano ante el nuevo tipo de migración emergente: la ambiental.

El segundo apartado de las conclusiones se enfoca en el potencial innovador en materia de políticas públicas en el sector medioambiental, donde se ejemplifican los grandes esfuerzos que ha realizado México por consolidar su política ambiental desde 1983 en sus Planes Nacionales de Desarrollo, sin embargo, se evidencia lo siguiente: El tema del medio ambiente tiene que ser considerado responsabilidad de toda la sociedad, no solamente de las dependencias de gobierno esto se logrará en la medida de que cada uno de los elementos que pertenecen e intervienen en el sector se responsabilice, participe y cumpla con el papel que le corresponde, porque aún se detecta que los planes y programas que existen actualmente carecen de un enfoque transversal.

El tercer apartado, enfocado en la creación de políticas públicas en materia de migración, y por ende de refugiados, se detecta lo siguiente: Las políticas públicas que se han desarrollado al respecto se han visto limitadas o insuficientes ante la creciente demanda de solicitudes de asilo en nuestro país, hay una falta de coordinación entre las instituciones encargadas de gestionar el tema, tampoco se muestra una cultura de innovación y, por último, el presupuesto para gestionar políticas púbicas tendientes a garantizar el respeto de los Derechos Humanos de los migrantes y refugiados, es insuficiente. 
Lo anterior nos lleva a la conclusión general de que la puesta en práctica de nuevos instrumentos de la Nueva Gestión Pública puede abonar a la construcción de políticas públicas en materia ambiental y migratoria. La clave es comprometer y corresponsabilizar a diversos actores en la gestión ambiental y migratoria, en la toma de decisiones, en la búsqueda de la transversalidad del ambiente en planes y programas.

El gran desafío en México es coordinar a todos los agentes, formar puentes y construir en conjunto una agenda de políticas públicas, que permitan la interacción y co-creación. Estos procesos pueden concebirse como el sustento para avanzar en políticas que sean capaces de acompañar un proceso emergente de la innovación social más allá de los ciclos políticos y contar con la resiliencia necesaria para darle continuidad en el tiempo a de lo que surja, como políticas del sistema ${ }^{14}$.

\section{BIBLIOGRAFÍA}

- Alto Comisionado de las Naciones Unidas para los Refugiados. Agenda para la protección de personas refugiadas en México 2019- 2024, México, disponible en:

https://www.acnur.org/es-mx/op/op_prot/5cfeadb34/agenda-para-la-proteccionde-personas-refugiadas-en-mexico-2019-2024.html.

- Alto Comisionado de las Naciones Unidas para los Refugiados. Buenas prácticas: Opciones migratorias para víctimas de desastres naturales, disponible en: https://www.acnur.org/buenas-practicas.html.

- Constitución Política de los Estados Unidos Mexicanos, disponible en: http://www.diputados.gob.mx/LeyesBiblio/pdf/1_080520.pdf.

- Centre for Research on the Epidemiology of Disasters - The United Nations Office for Disaster Risk Reduction (CRED-UNISDR). The human cost of weather related disasters 1995-2015, Louvain 2016, p. 5, en:

https://www.unisdr.org/files/46796_cop21weatherdisastersreport2015.pdf

- GATICA M., Sebastián, Innovación social: hacia una nueva aproximación del rol de estado reflexiones, Secretaría Ejecutiva del Consejo Nacional de Innovación para el Desarrollo (CNID), Santiago, Chile, enero.p.40

\footnotetext{
14 Véase GATICA M., Sebastián, Innovación social: hacia una nueva aproximación del rol de estado reflexiones, Secretaría Ejecutiva del Consejo Nacional de Innovación para el Desarrollo (CNID), Santiago, Chile, enero 2016, p. 40.
} 
- HOLMES, SIR John, Comentario de apertura en la exposición de ayuda humanitaria internacional y conferencia de desarrollo de Dubái "Conferencia DIHAD 2008 “, 8 de abril de 2008. Disponible en:

http://www.reliefweb.int/rwarchive/rwb.nsf/db900sid/YSARDHL88?Open Document. 8.

- Ley General de Cambio Climático, en:

http://www.diputados.gob.mx/LeyesBiblio/pdf/LGCC_130718.pdf

- Ley de Migración, en:

http://www.diputados.gob.mx/LeyesBiblio/pdf/LMigra_130420.pdf

- Ley sobre Refugiados, Protección complementaria y Asilo Político, en: http://www.diputados.gob.mx/LeyesBiblio/pdf/LRPCAP_301014.pdf

- NANSEN INITIATIVE, The Nansen Initiative. Disasters and Cross-border Displacement. Recuperado de https://www.nanseninitiative.org/

- ORGANIZACIÓN DE LAS NACIONES UNIDAS. Objetivos para el Desarrollo Sostenible. 2015, en: https://www.un.org/sustainabledevelopment/ es/development-agenda/.

- ORGANIZACIÓN INTERNACIONAL PARA LAS MIGRACIONES (OIM). Migration, Environment and Climate Change: Assessing the evidence, 2009, p.19 en: https://publications.iom.int/system/files/pdf/migration_and environment.pdf.

- PANEL INTERGUBERNAMENTAL DE EXPERTOS SOBRE CAMBIO CLIMÁTICO DE LA ONU (IPCC), Climate Change 2014. Impacts, Adaptation, and Vulnerability. Summary for Policymakers, p. 5, en: https://www.ipcc.ch/site/assets/uploads/2018/02/ar5_wgII_spm_en.pdf.

- SISTEMA DE LAS NACIONES UNIDAS PARA LA COORDINACIÓN DE LA REDUCCIÓN DEL RIESGO DE DESASTRES (UNISDR). La Reducción del Riesgo de Desastres: Un Instrumento para alcanzar los Objetivos de Desarrollo del Milenio. Suiza, 53 p.

- VARIOS, Perspectivas económicas de América Latina 2018: Repensando las instituciones para el desarrollo. Editions OCDE, París. Disponible en: http://dx.doi.org/10.1787/leo-2018-es.

- YAMAMOTO, L. "La migración ambiental en la Agenda 2030 en los planes de Sudamérica: argentina Bolivia y Perú", en VARIOS, Migraciones en las Américas. Colegio de México, 2019. pp. 415, 416. 
